\title{
Abdominal Belts for Manual Handling IN INDUSTRY: The evidence for and against
}

\begin{abstract}
SUMMARY The paper reviews research on the use of abdominal belts for industrial back injury prevention programmes. The evidence for biomechanical, BY RS BRIDGER physiological and psychophysical effects of belt use is presented, following a brief theoretical discussion. Although there is some laboratory evidence that abdominal belts protect the spine when lifting, the findings of field studies are equivocal. Previously injured workers seem to benefit the most böth from "back school" training combined with wearing abdominal belts at work. However, far from being the solution to industrial manual handling problems, abdominal belts have only a small part to play in comprehensive risk management programmes aimed at reducing back problems in the workplace.
\end{abstract}

\section{KEY WORDS: ABDOMINAL BELTS, OCCUPATIONAL BACK PAIN, PREVENTION}

\section{INTRODUCTION}

"Ergogenic corsets", "back belts" or "abdominal belts" are currently being evaluated as a form of protection against low-back injury for use in industrial manual handling operations (Magnusson et $a l^{1}$, Soh et $\left.a l^{2}\right)$. Unlike other products designed to safeguard the health of industrial workers, the effectiveness of these devices remains unproved (Rabinowitz $e t a l^{3}$ ). In the present paper, the results of a manual search of the literature on ergonomics and industrial safety was carried out. The evidence for and against the prescription of abdominal belts in industry is reviewed. Using an analogy with other medical products, if belts are to be accepted as a form of protection against industrial injury, a body of evidence from laboratory and clinical (industrial field) trials is needed which demonstrates

- That the use of the belts confers some kind of biomechanical advantage which will protect the spine from injury in the workplace

- That the occupational use of the devices does not have unwanted or unexpected side effects which impact negatively on the health of the worker

\section{THEORETICAL BACKGROUND}

The practice of wrapping materials around the waist with the aim of improv-

\section{CORRESPONDENCE}

By RS Bridger Ph.D.

Head Ergonomics Group, Department of Biomedical Engineering, UCT Medical School, Observatory 7925 , 021 406-6541 (bus) 0216862820 (residence), e-mail bridger@anat.uct.ac.za ing posture and poise is found throughout history and across cultures. Shah ${ }^{4}$ for example, reports that in Nepal, most people who lift and carry heavy weights wrap a 5 metre length of cloth (called a "Patuka") around the waist before work. Anecdotally, it is thought to reduce the prevalence of occupational lowback pain.

It was Keith ${ }^{5}$ who first proposed that intra-abdominal pressure (IAP) resulting from contraction of the abdominal muscles during lifting acts to reduce the load on the spine. Morris et al used a biomechanical approach to support the argument that IAP reduces spinal compression directly, by the upward hydraulic

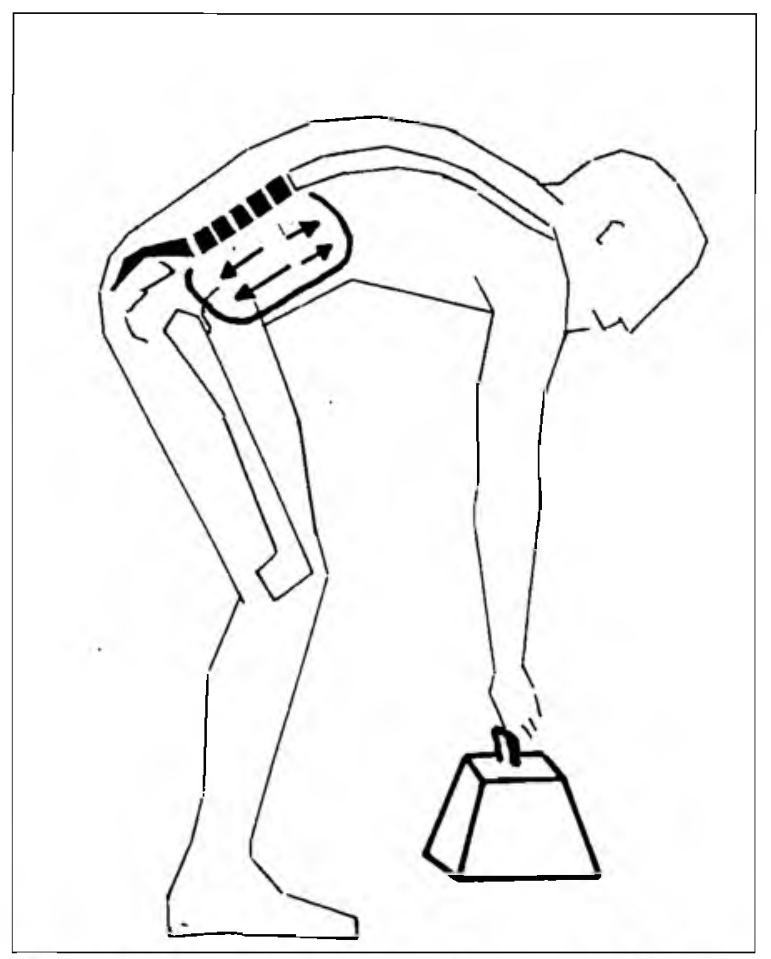

Figure 1. The abdominal mechanism in lifting action on the diaphragm, and by exerting an extensor moment about the spine (Figure 1). The extensor moment thus produced, was thought to assist the back extensors

For a given load, IAP assistance would reduce the back muscle extensor force required and therefore the compressive loading on the spine.

If IAP does lower spinal compression by exerting a hydraulic tensile force on the diaphragm and a spinal extensor moment, then abdominal belts would be hypothesised to augment this effect by assisting the abdominal muscles in generating IAP. Furthermore, since IAP is generated by abdominal muscle contraction and since abdominal muscle contraction is associated with an increase in the flexion moment about the spine (McGill and Norman ${ }^{7}$ ), abdominal belts would facilitate increased IAP and a lowered flexion moment.

Alternatively, IAP may protect the loaded lumbar spine indirectly. Contraction of the abdominal musculature sets up lateral forces which act on the spine via the pelvis, ribcage and lumbodorsal facia, acting like guy ropes which stabilise a mast inside a now, rigid, cylinder. This argument was echoed by Aspden $^{8}$, using a novel biomechanical approach (based on the mechanics of masonry arches). Aspden argued that the more an arch (i.e. the lumbar spine, in this case) is com- 
pressed, the stiffer and more resistant to buckling it becomes. IAP may therefore help to maintain the alignment of the motion segments and prevent injury due to small displacements of structures at the level of the facet joints and intervertebral discs.

Table 1 summarises the possible benefits and possible negative side effects of occupational wearing of abdominal belts in industry.

\section{DOES IAP REDUCE SPINAL COMPRESSION WHEN LIFTING?}

McGill and Norman ${ }^{7}$ used biomechanical models to calculate the L4/L5 reaction force and the IAP and abdominal flexion moment in a lifting task. The forces and the moment created by the increased IAP were not sufficient to overcome the flexion moment and resulting lumbar compression caused by the increased abdominal muscle activity. Greater levels of IAP could only be created by further abdominal compression according to McGills model, leading to the conclusion that IAP may not alleviate spinal compression at all.

Rather than reducing spinal compression, it seems more likely, as suggested by Chaffin ${ }^{9}$, that abdominal muscle activity in lifting tasks is part of a complex process of co-contraction of many different muscles which act to stabilise the trunk. Although researchers often choose to model lifting tasks two-dimensionally (the ubiquitous sagittal plane lift), in reality the trunk is a three dimensional structure designed to move in three dimensions. Oblique/transverse muscle cocontraction during sagittal lifting may just be the natural response of the threedimensional trunk control and stabilisation system.

If this view is correct, increased IAP during lifting may be no more than a side effect of the operation of this system.

\section{DO ABDOMINAL BELIS INCREASE IAP WHEN WORN?}

McGill et a ${ }^{10}$ measured back extensor EMG and IAP when subjects lifted weights wearing a competition weight lifter's belt. Although IAP did increase when the belt was worn (from $99 \mathrm{mmHg}$ to $120 \mathrm{mmHg}$ ) there was no corresponding reduction in back extensor activity. When subjects held their breath when lifting, increases in IAP were also observed and were accompanied by reductions in back extensor EMG - irrespective of whether a belt was worn.
Although there is no direct evidence one way or the other, increased IAP accompanying belt use may increase the risk of trunk injury (such as umbilical herniation) or increase load on the cardiovascular system by impeding venous return to the heart.

\section{DOES WEARING AN ABDOMINAL BELT REDUCE BACK MUSCLE FATIGUE WHEN LIFTING?}

Ciriello and Snook ${ }^{11}$ measured fatigue of the back extensors in 13 male industrial workers who lifted average loads of $28.1 \mathrm{~kg}, 4.3$ times per minute for four hours a day. A belt was worn on two of the days. Maximum isokinetic endurance decreased by 9 to $11 \%$ after four hours of lifting. This change was not significantly different when a belt was worn, neither were there differences in the power spectrum of the EMG signal as indicated by median frequency analysis (DeLuca ${ }^{12}$ ) Subjective ratings of effort were not influenced by back belt wearing.

\section{DOES WEARING AN ABDOMINAL BELT HAVE AN OVERALL PROTECIIVE EFFECT?}

Reilly and Davies ${ }^{13}$ evaluated a weightlifters belt by having subjects lift a $30 \mathrm{~kg}$ weight for eight sets of twenty repetitions. Spinal shrinkage as a result of the task-induced loading (using stadiometry, Eklund and Corlett $\left.{ }^{14}\right)$ was reduced by $49 \%$ when the belt was worn (from $4.08 \mathrm{~mm}$ to $2.08 \mathrm{~mm}$.) Spinal shrinkage is measured by recording reductions in stature over a period of lifting. The reductions are caused by the egress of fluid from the intervertebral discs due to the loading. Spinal shrinkage is used as an index of the cumulative compressive loading on the spine during the performance of a task.

Perceived exertion was also lower with the belt . Magnusson et al compared lifting with and without a belt when subjects lifted $10 \mathrm{~kg}$. from floor to desk height twice per minute for 5 minutes. Spinal shrinkage was lower when the belt was used as was back muscle EMG (normalised with respect to each subject's maximum voluntary contraction).

\section{DOES WEARING AN ABDOMINAL BELT GIVE LIFTERS AN INCREASED SENSE OF STABILITY AND SECURITY?}

Both McGill et $a l^{10}$, Reddell et $a l^{15}$ and Magnusson et al report that wearing either competitive weightlifter's belts or abdominal belts for industrial workers increases the sense of security. McCoy $e t$ $a l^{16}$ found that subjects self-selected weights which were $19 \%$ heavier when they were wearing belts.

This finding is in agreement with the predictions of "Risk Hoemoestasis Theory" which predicts that the safer we perceive ourselves to be, the more dangerously will we behave. It has been demonstrated, for example, that drivers of cars equipped with air bags drive more aggressively, offsetting the effect of the air bag for the safety of the driver and increasing the risk of death to other road users and pedestrians (Peterson et $a l^{17}$ ). The theory predicts that abdominal belts will cause users to lift in a more dangerous way or attempt to lift heavier loads. A better way to improve industrial safety is to make people more aware of the dangers inherent in manual handling of loads and to minimise the danger by mechanising the task or reducing the load to be lifted.

\section{DO ABDOMINAL BELTS PROTECT INDUSTRIAL WORKERS IN PRACTICE?}

Walsh and Schwartz ${ }^{18}$ divided 90 grocery warehouse workers into three groups in a six month investigation. Group 1 (control) received no intervention. Group 2 received a 1 hour training session on back pain prevention. Group 3 received the training and a moulded spinal orthotic brace to be worn at work. There were no significant differences in injury rates or productivity between the three groups over the study period. Lost time was significantly lower in Group 3, however ( 2.5 days lower, on average). The groups were further divided into high and a low risk workers. High risk workers in Group 3 had significantly fewer injuries and lost time suggesting that previously injured workers will benefit the most from this form of intervention.

Reddell et $a l^{15}$ evaluated an abdominal belt and back programme amongst a group of airline baggage handlers. Lost workdays and back injuries were not reduced, but back injuries increased and were more severe after belt use was discontinued. Mitchell et al ${ }^{19}$ examined belt use. training, back injury and lost time in a US Air Force base. The predictors of low back injury were as expected - time spent lifting and previous back injury. Back training programmes were found to have a small preventative effect as did the use of back belts. However, the costs of treating injuries when they did occur were found to be higher amongst belt wearers leading the authors to conclude that belt use was not indicated in this type of work. 


\section{DOES OCCUPATIONAL ABDOMINAL BELT WEARING DE- CONDITION THE TRUNK MUSCULATURE?}

The evidence suggests not. McGill et al ${ }^{10}$ noted that even though belt wearing does reduce abdominal muscle EMG during lifting, the reduction is not large. Even when lifting heavy loads (above $70 \mathrm{~kg}$ ) without a belt, peak abdominal muscle EMG levels are a small percentage of those observed when subjects exert a maximum voluntary contraction of their abdominal muscles. Therefore, the abdominal training effect of lifting is likely to be small (compared, for example with coughing or laughing). Walsh and Schwartz ${ }^{18}$ measured abdominal strength before and after the six month study period and found no evidence for a reduction in abdominal strength amongst belt wearers compared with controls.

\section{IS ABDOMINAL BELT WEARING HAZARDOUS FOR WORKERS WITH LATENT CORONARY HEART DISEASE?}

It is known that both belt wearing and breath holding while lifting increase IAP and intra-thoracic pressure. Hunter et $a l^{20}$ had subjects hold $40 \%$ of their maximum weight in the dead lift posture for two minutes. Blood pressure and heart rate were higher when the belt was worn leading to the conclusion that cardiac compromised individuals are probably at greater risk when exercising while wearing back supports. It is known that increased intra-truncal pressure hinders venous return to the heart and is

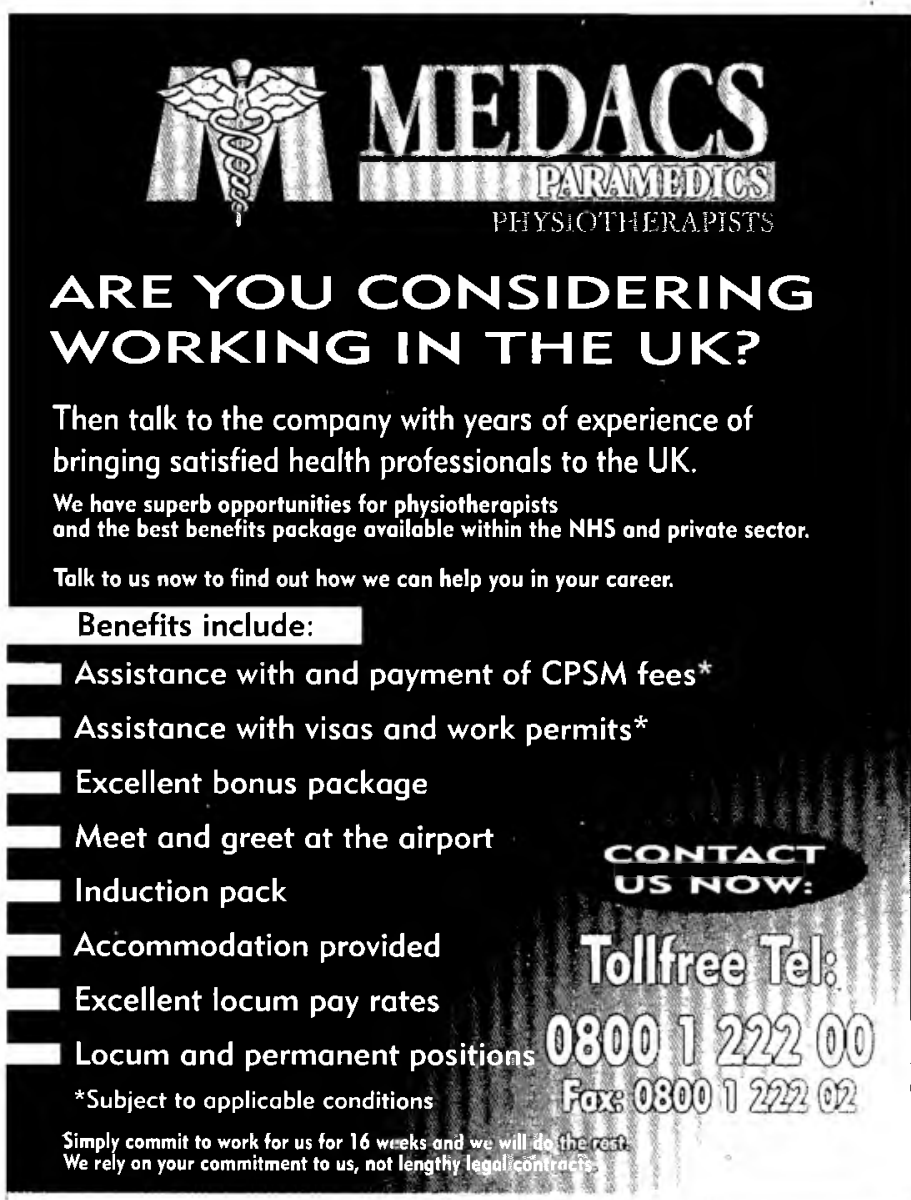

Medacs, The Old Surgery, 49 Otley Street, Skipton, North Yorkshire, BD23 IET England Medacs is the UK's leading health professional recruitment agency. followed by a rush upon pressure release which can cause unconsciousness in extreme cases. McGill et al ${ }^{10}$ speculate that this may explain the high incidence of heart attacks amongst unfit people carrying out cyclic lifting activities such as snow shovelling.

\section{LIMITATIONS OF THE STUDIES}

Many of the fundamental studies cited are of interest because they elucidate the mechanisms underlying injury and protection against injury. The main drawbacks are that they are carried out on small numbers of young subjects, often students, who are not representative of likely industrial users. A major weakness of those studies which have found modest benefits from abdominal belt usage is that posture was not measured. It is possible that belt wearing altered subjects' posture when lifting and that the benefit was, indirect, due to the change in posture rather than a protective effect of the belt itself.

\section{CONCLUSIONS AND RECOMMENDATIONS}

1. Although the mechanism is unclear, belts do seem to provide some type of protection in light tasks such as grocery selection (where the loads are normally light but the lifting and bending frequency is great). Previously injured workers benefit the most.

2 . With heavy tasks, the evidence is less clear and there are real concerns about whether belts create a false sense of security and encourage workers to lift heavier weights.

3. There are real concerns about possible side effects of occupational belt use. Although there is no evidence for deconditioning of the trunk muscles, chronically increased IAP in the workplace may bring with it cardiovascular and other risks.

Clearly, these devices should never be issued as quick fixes to "solve" manual handling problems in industry. A proper assessment of the work environment should first be carried out to determine the scope for amelioration through mechanisation, redesign (reduction) of the loads or improvement of the work environment (see Bridger ${ }^{21}$, for example). The cardiovascular and general health status of the workforce should be well-understood before considering belts. Belts should only be issued as part of a comprehensive programme of risk management and only worn for short periods for the performance of specific tasks. 


\section{REFERENCES}

I. Magnusson M, Pope MH, Hansson T. Does a back support have a positive biomechanical effect? Applied Ergonomics, 1996; 27(3):201-205

2. Soh TN, Parker PL Crumpton LL et al. 1997. An investigation of respiration while wearing back belts. Applied Ergonomics, 1997, 28(3): 189-192.

3. Rabinowitz D, Bridger RS, Lambert M. Lifting technique and abdominal belt usage: a biomechanical, physiological and subjective investigation. Safety Science (In Press).

4. Shah RK. A pilot survey of the traditional use of the patuka round the waist for the prevention of back pain in Nepal. Applied Ergonomics 1993; 24:337-344.

5. Keith A. Man's posture: its evolution and disorders. Lecture VI: The adaptations of the abdomen and its viscera to the orthograde posture. British Medical Journal 1923; 1:587-590

6. Morris JM, Lucas DB, Bresler B. Role of the trunk in the stability of the spine.

Journal of Bone and Joint Surgery 1961; 43A: 327-351.

7. McGill S, Norman RW. Reassessment of the role of intra-abdominal pressure in spinal compression. Ergonomics 1987; 30(11):

1565-1588.

8. Aspden RM. The spine as an arch: A new mathematical model. Spine 1989;14: 266274.

9. Chaffin D. Biomechanical modelling of the low back during load lifting. In Designing a Better World, Proceedings of the 1 Oth Congress of the International Ergonomics Association, Sydney, Australia. Ergonomics Society of Australia Inc, 1988. 10. McGill S, Norman RW, Sharratt. The effect of an abdominal belt on trunk muscle activity and intra-abdominal pressure during squat lifts. Ergonomics 1990; 33(2):146-160.

11. Ciriello VM, Snook SH. The effect of back belts on lumbar muscle fatigue. Spine 1995;20(11): 1271-1278

12. DeLuca CJ. Myoelectric manifestations of localised muscle fatigue. Critical Reviews of Biomedical Engineering 1985, 11:251279.

13. Reilly T Davies S. Effects of a weightlifting belt on spinal loading during performance of the dead lift. In Sport, Leisure and Ergonomics, edited by $\mathrm{G}$ Atkinson and T Reilly, E and FN Spon, 1995.

14. Eklund JAE, Corlett EN. Shrinkage as a measure of the effect of load on the spine. Spine 1984;9:189-194.

I5. Reddell CR, Congelton JJ, Huchingson Rd, Montgomery JF. An evaluation of a weightlifting belt and back injury protection prevention training class for airline baggage handlers. Applied Ergonomics

1992;23(5):319-329.

16. McCoy MA, Congleton JJ, Johnston WL, Jiang BC. The role of lifting belts in manual lifting. International Journal of Industrial Ergonomics 1988; 2: 259-266.

17. Peterson S, Hoffer G, and Millner E. Are drivers of air-bag-equipped cars more aggressive? A test of the offsetting behaviour hypothesis. 1995. Journal of Law and Economics, 38: 251-265.

18. Walsh NE Schwartz MS. The influence of prophylactic orthoses on abdominal strength and low back injury in the workplace. American Journal of Physical Medicine and Rehabilitation 1990;69(5):245-250.

19. Mitchell RV, Lawler FH, Bowen D, Mote W, Asundi P, Purswell J. Effectiveness and cost effectiveness of employer-issued back belts in areas of high risk for back injury. Journal of Occupational Medicine 1994; 36(1):90-94.

20. Hunter GR, McGuirk J, Mitrano N, Pearman P, Thomas B, Arrington R. The effects of a weight training belt on blood pressure during exercise. Journal of Applied Sports Science Research 1989; 3(1):13-18.

21. Bridger RS. Introduction to Ergonomics. New York: McGraw-Hill. 1995.
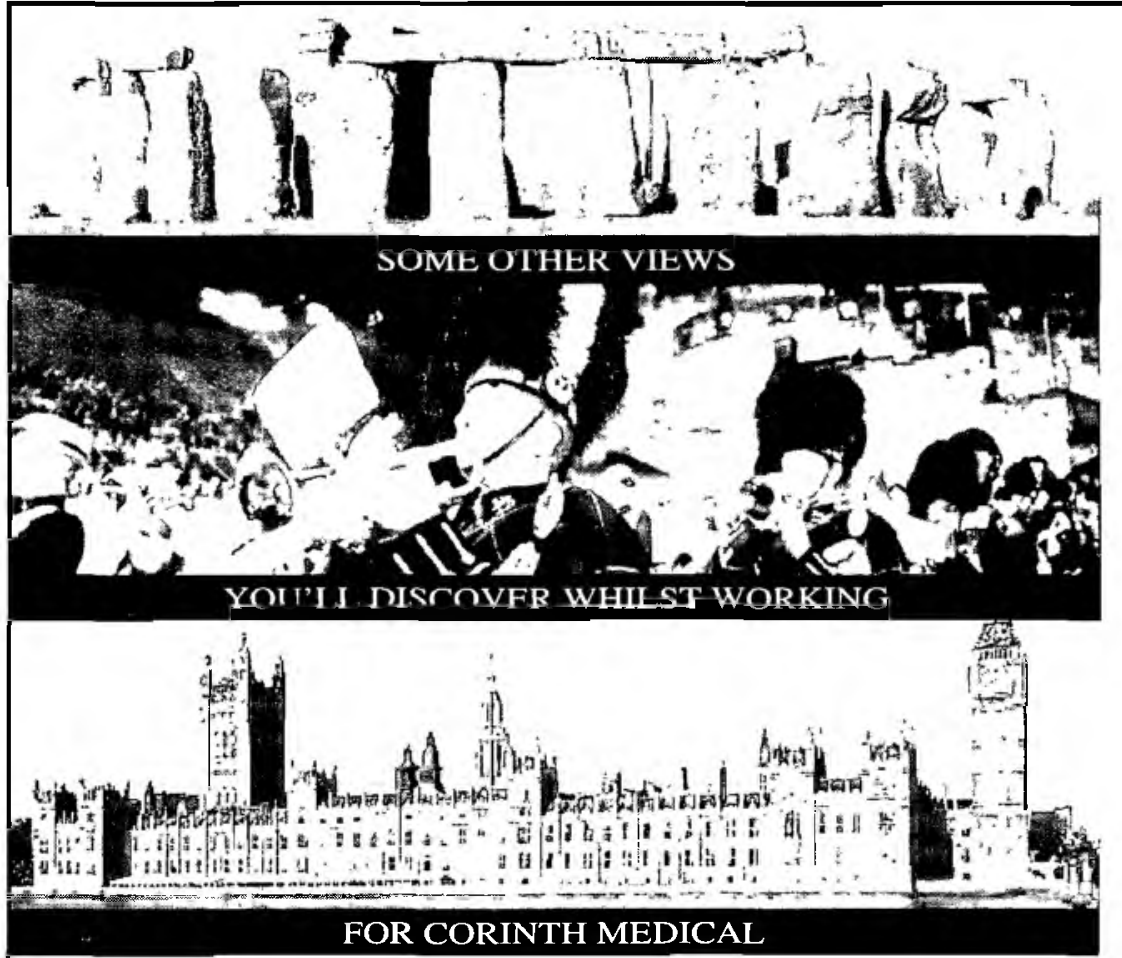

Post to: Corinth Medical 5 Theobald Court, Theobald Street Borehamwood, Hertfordshire WD6 4RN. ENGLAND Tel: 09441812070234 Fax: 09441812076894 Medical
In order to get the most out of your working holıday in Britain, you'll want the expert care you can only gain from Cornth. With almost thrty years experience we ve grown to be the leading specialist Employment Agency in our field by helping Physiotherapists from all over the world combine business with pleasure: giving them the opportunity to work with the UK's leading hospitals and helping them take time out to enjoy the different cultures and sights. What 's more, as well as top rates of pay and an excellent package of benefits, you won't be tued to any bunding contracts and you won't be charged for our services. We'll simply offer you the widest selection of jobs and supply fruendly and confidentral advice on al! aspects of working through an agency.

Want us to put you in the picture?

If so. complete the coupon below and send tt to our Recruitment Manager. Debi Faulder MCSP SRP and she will send you our FREE ' Workıng Holidays in Britain' Information Pack. Altematıvely. you can call us TOLL-FREE on 0800-99-8168 (24 hours)

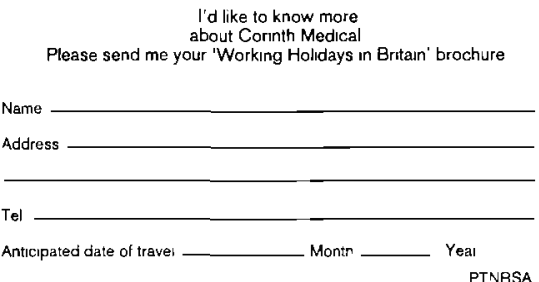

